\title{
Accesibilidad urbana y conectividad de los centros de empleo en Culiacán
}

Natalia Correa Delval ${ }^{1}$

Recibido: 02-10-2020 | Versión final: 02-04-2021

Resumen El análisis del acceso a las oportunidades de la ciudad es el objetivo de la evolución del paradigma de movilidad a uno de accesibilidad urbana. En este artículo, dicho análisis está enmarcado por las teorías de la ciudad monocéntrica y la centralidad de la red, esta última como aproximación a la accesibilidad con base en la infraestructura vial que soporta los viajes. El presente estudio se enfoca en la concentración de las actividades laborales y la conectividad como cualidad de los vínculos relevantes entre el empleo y la población ocupada. Para el abordaje de la conectividad se utilizaron cuatro medidas diferentes de centralidad por medio de herramientas de procesamiento en SIG: por cercanía, grado de centralidad, por intermediación y "eigenvector", procurando un análisis múltiple de la red. Con respecto a la concentración del trabajo en la ciudad, se aplicaron los métodos de identificación de subcentros urbanos: picos de densidad de empleo en zonas contiguas y umbrales de concentración. Para estos métodos se utilizó información del INEGI, disponible a nivel nacional en México. Los resultados revelan cuantitativamente los rasgos de conectividad de la red de la ciudad y la fuerza del centro urbano debido a la concentración de empleos y su conectividad. De igual forma para cada centro de empleo, según el número de puestos ocupados, población ocupada con accesibilidad potencial y la conectividad de su área de servicio, expresada por las diferentes formas de centralidad.

Palabras clave: Acceso; centralidad; red; ciudad monocéntrica

Citación

\section{Urban Accessibility and Connectivity of Employment Centers in Culiacan}

Abstract

\begin{abstract}
The analysis of access to opportunities in the city is the objective of the evolution of the mobility paradigm into an accessibility paradigm. This analysis is framed in the theories of the monocentric city and the network centrality as an approach to accessibility based on road infrastructure supporting travel. This study focuses on the concentration of work activities and connectivity as a quality of the relevant links between employment and the employed population. For the connectivity approach, four different centrality measures were used by means of GIS processing tools: closeness, degree of centrality, betweenness and "eigenvector", searching for a multiple analysis of the network. With regard to the concentration of work in the city, the applied methods to identify urban sub-centers were: employment density peaks in contiguous areas and concentration thresholds. Information from INEGI, available at the national level in Mexico, was used for all these methods. The results quantitatively reveal the connectivity features of the city network and the strength of the urban center due to the concentration of jobs and connectivity. In the same way for each employment center, according to the number of job positions occupied, employed population with potential accessibility and the connectivity of its service area, expressed by the different forms of centrality.
\end{abstract}

Keywords: Access; centrality; network; monocentric city

${ }^{1}$ Doctora en Ciudad, Territorio y Sustentabilidad por la Universidad de Guadalajara, profesora investigadora en la Facultad de Arquitectura de la Universidad Autónoma de Sinaloa (ORCiD: 0000-0002-5119-3020, WoS ResearcherID: AAK-1603-2021). Correo de contacto: natalia.correa@uas.edu.mx 


\section{Introducción}

La accesibilidad es un concepto que se refiere a las posibilidades que otorgan el transporte y los usos del suelo para que las personas alcancen un determinado destino según sus deseos o necesidades (Geurs y van Wee, 2006). Analizar y medir esta cualidad del espacio urbano es el objetivo de la evolución del paradigma de la movilidad a uno de la accesibilidad (Farrington, 2007). En relación a ello, al analizar la accesibilidad en la red que da soporte a los desplazamientos de todo tipo en la ciudad, es necesario abordar la conectividad como cualidad de vínculos relevantes entre objetos y actividades interrelacionadas (Figueroa y Rozas, 2005).

Por su parte, en cuanto a los motivos de las personas para desplazarse por la ciudad, cada decisión depende de las oportunidades disponibles (Boarnet y Crane, 2001) y estas oportunidades disponibles están estrechamente relacionadas con la distribución de usos del suelo. En lo que respecta a los viajes por motivo de trabajo, estos han sido objeto de estudio desde la década de los años sesenta y setenta debido a la suburbanización y según el ingreso (Mills, 1972), pasando por enfoques como el balance entre trabajo y vivienda (Cervero, 1997), así como los costos de traslado (Cervero et al., 1997). Aunque, por un lado, cualquier motivo de movilidad cotidiana merece la misma importancia (MirallesGuasch, 2002), por otro la cantidad de viajes por trabajo en las ciudades, ha permitido que la generación de información en torno a ella haya sido considerada necesaria de obtener en México por el Instituto Nacional de Estadística, Geografía e Informática (INEGI) en el último estudio de tipo encuesta a nivel nacional (INEGI, 2015).

En ese orden de ideas, el objetivo del presente estudio es conocer la accesibilidad potencial en los principales centros de empleo de una ciudad media, utilizando las características de centralidad de la red de sus áreas de influencia y de la ciudad en general.

En relación al objetivo, las metodologías de identificación de subcentros son útiles para identificar los centros atractores de viajes por motivo de trabajo. Sin embargo, algunas de estas medidas y las de accesibilidad requieren de información representativa de los desplazamientos cotidianos del caso de estudio. Al respecto, la falta de información estadística actualizada sobre movilidad urbana en la mayoría de las ciudades de México es uno de los principales retos para afrontar cuando se trata de conocer la dinámica de los desplazamientos cotidianos (ONU-Hábitat, 2015) y la accesibilidad urbana. Ante esta situación, se utilizó la densidad laboral $\left(\mathrm{LTL} / \mathrm{Km}^{2}\right)$ para identificar los centros de empleo, calculada con datos de las unidades económicas (INEGI, 2019). Así mismo, se propone la utilización de fuentes de información geográfica y estadística generadas con mayor frecuencia y periodicidad constante, como las del INEGI en México y que pueden analizarse con el conjunto de herramientas para el cómputo de la centralidad de la red que brindan los sistemas de información geográfica (SIG).

Con la aplicación de las medidas de centralidad para conocer la conectividad en la que se emplazan los centros de empleo en Culiacán, se demuestra que la monocentralidad de la ciudad se transfiere a la accesibilidad urbana en el ámbito laboral, mientras que en el aspecto metodológico se logra un acercamiento al entendimiento de la accesibilidad potencial y la posibilidad de tener alternativas para mejorar la dimensión espacial de la movilidad, con base en la centralidad de la red.

\section{Trabajos relacionados}

En su disertación, Geurs (2006) argumenta la complejidad de la operacionalización de la accesibilidad y lo común que ha sido evaluar la accesibilidad con medidas de fácil interpretación como los niveles de congestión o la velocidad, las cuales implican desventajas metodológicas. En este sentido se han

ACE, 16 (47) CC BY-ND 3.0 ES | UPC Barcelona, España | Accesibilidad urbana y conectividad de los centros de empleo en Culiacán. DOI: http://dx.doi.org/10.5821/ace.16.47.9694 
construido medidas que consideran más y diversas variables, tales como las de separación espacial (Geurs y van Eck, 2001), de contorno (Bhat, y otros, 2001), de gravedad (Geurs y van Eck, 2001), de competencia (Geurs y van Eck, 2001), de utilidad (Geurs K., 2006) y de red (Porta et al., 2006). De entre las anteriores, las medidas de gravedad miden el potencial de interacción entre orígenes y destinos, que son las más usadas en la práctica debido a su facilidad de implementación, interpretación y comunicabilidad (Geurs y van Wee, 2004). Uno de los requisitos para utilizar esta medida es la existencia de un costo de interacción espacial, que puede ser la distancia recorrida o el tiempo de viaje entre origen y destino, expresada como una función de decaimiento. Ahora bien, las medidas de red miden la centralidad a través de toda la red de movilidad urbana, además son más intuitivas y también permiten incorporar el costo de la interacción espacial en su análisis.

Con relación a lo anterior, en la investigación de Garrocho y Campos (2006), se propone una medida de accesibilidad a servicios públicos que puede ser utilizado en planeación urbana en el contexto mexicano, definiendo operacionalmente la accesibilidad como un potencial de interacción entre las unidades de servicios disponibles en la ciudad y la población objetivo, considerando para ello la dimensión de la oferta como un factor de atracción y la fricción de la distancia como la distancia lineal entre el centroide de cada área geoestadística básica (AGEB) (origen donde radica la población objetivo) y la unidad de salud (destino).

Por su parte, en el estudio de Suárez y Delgado (2007), se utilizan las medidas de gravedad para analizar la accesibilidad a empleos en la Zona Metropolitana de la Ciudad de México, con el objetivo de presentar evidencias que definan la calidad y condición de policentrismo, monocentrismo con dispersión y desarrollo en corredores de la metrópoli. Los elementos que se consideraron como base para el desarrollo de las medidas se basan en el índice de accesibilidad básico propuesto por: número de empleos en un determinado centro de empleo, la distancia mediante la red de transporte entre la zona de empleo y otra de interés, así como un coeficiente de decaimiento calculado empíricamente.

Como se ha venido expresando, la utilización de un potencial de interacción y el papel de la red urbana como soporte de dichas interacciones han sido abordados ampliamente. Adicionalmente, el análisis de las redes ha tenido un desarrollo prominente en la investigación geográfica y urbana. Ejemplo de ello son los estudios que involucran la vulnerabilidad urbana (Demšar et al, 2008; Sarlas et al., 2020), la inequidad (Liu et al., 2017), la categorización de las estructuras de la ciudad (Crucitti et al., 2006) o la conectividad (Castanho et al., 2017; Hannemann y Derudder, 2014).

En este sentido, Batty (2013) sugiere que, para entender las ciudades, estas deben verse no como simples lugares en el espacio, sino como sistemas de redes y flujos. Así, en las últimas décadas se han desarrollado diferentes formas de abordar esta perspectiva. Una de ellas, la "sintaxis del espacio", es un marco teórico y práctico en el cual el espacio urbano está representado por vialidades como nodos e intersecciones como aristas, donde se dan las interacciones humanas y el espacio construido (Hillier y Hanson, 1989; 1999).

Otra perspectiva desde las redes consiste en la representación del sistema espacial utilizando un grafo primario, donde las aristas representan las calles y los nodos son las intersecciones de ellas (Porta et al., 2006; Sevtsuk y Mekonnen, 2012). Este acercamiento se caracteriza por conservar los rasgos topológicos de la red de calles para poder integrar la distancia euclidiana en el análisis de los sistemas. A su vez, esto es fundamental en el desarrollo de herramientas de sistemas de información geográfica (SIG) para el cómputo de diferentes tipos de medidas de red (Sevtsuk y Mekonnen, 2012).

ACE, 16 (47) CC BY-ND 3.0 ES | UPC Barcelona, España | Accesibilidad urbana y conectividad de los centros de empleo en Culiacán. DOI: http://dx.doi.org/10.5821/ace.16.47.9694 
A partir de estos antecedentes, el presente artículo brinda una alternativa de aproximación a la accesibilidad de los centros de empleo en una ciudad monocéntrica, utilizando el soporte de la red de calles.

\section{Accesibilidad urbana a los lugares de trabajo en la ciudad monocéntrica}

\subsection{Estructura de la ciudad monocéntrica}

Para comprender el concepto de estructura de la ciudad se consideran los tres modelos clásicos de la estructura urbana que surgieron en la Escuela de Sociología Urbana en Chicago a principios del siglo XX: el modelo concéntrico de Burgess (1925), el modelo sectorial de Hoyt (1939) y el modelo polinuclear de Harris y Ullman (1945). El modelo de Burgess explica las transiciones de la ciudad con base en círculos concéntricos a partir de un centro. Después, Hoyt propuso un modelo donde el crecimiento obedece más a vías de comunicación y, posteriormente, el modelo polinuclear propuesto por Harris y Ullman explica el desarrollo de la ciudad en forma de núcleos de usos de suelo separados entre sí.

En referencia a lo anterior, Burgess (1925) pone la atención en el espacio central de la ciudad, o a lo que denomina distrito central de negocios (CBD por sus siglas en inglés), al cual se le atribuyen zonas que gravitan a su alrededor en orden hacia el exterior. Esta teoría del modelo concéntrico considera que la competencia por las localizaciones que generan mayores beneficios, determina el precio del suelo, que este a su vez define la distribución de usos de suelo y, como consecuencia, se genera la segregación de ciertas áreas con respecto a otras. Posteriormente, Clark (1951) plantearía una ley que establece la tendencia a la disminución de densidad con el aumento de la distancia respecto al centro. Al respecto, William Alonso (1964) desarrolló un modelo económico espacial en el cual estableció que la localización de una actividad depende de los beneficios económicos que pueda obtener si está más cerca del centro. Adicionalmente, según Cadwallader (1996), en los modelos de estructura urbana central los actores y la población en general se benefician por su ubicación respecto al núcleo de la ciudad.

Según Bertaud (2004), en la actualidad algunas estructuras espaciales son más compatibles con objetivos de tipo ambiental y social, demostrando que las ciudades monocéntricas, densas y uniformemente urbanizadas tienen condiciones favorables para el transporte público y pueden reducir significativamente la longitud de los viajes, consiguiendo así la reducción de emisiones contaminantes. No obstante, esto también concuerda con el funcionamiento de los modelos descritos anteriormente, teniendo valores del suelo más elevados en el centro, que reducen la superficie habitacional del centro mientras que aumenta en zonas periféricas. Así mismo, Bertaud (2004) sostiene que la evidencia empírica de ciudades en Europa y Asia demuestran que las actividades en los centros de las ciudades mantienen vivo el modelo monocéntrico, aunque ya en muchos casos con solo una fracción de los empleos de la ciudad.

Con respecto a la estructura urbana de las ciudades medias en México, Álvarez de la Torre (2017) demuestra en su estudio que la vivienda de alquiler, como objeto de consumo cuya ubicación está vinculada a la accesibilidad a servicios, transporte y centros de trabajo, se desplazó del centro a otros lugares de la ciudad durante la última década del siglo XX. Como consecuencia, la segregación residencial producida por los diferentes valores del suelo implica la concentración de servicios, oficinas y comercios, generando centralidades basadas en la accesibilidad de vialidades, especialmente de tipo radial (González, 2011).

ACE, 16 (47) CC BY-ND 3.0 ES | UPC Barcelona, España | Accesibilidad urbana y conectividad de los centros de empleo en Culiacán. DOI: http://dx.doi.org/10.5821/ace.16.47.9694 


\subsection{Accesibilidad urbana y conectividad de los centros de empleo}

Como parte de la dinámica de las ciudades, la movilidad impacta en las condiciones de seguridad, competitividad y prosperidad, del mismo modo que impone costos sociales y ambientales, que para los individuos de una sociedad definen sus formas de interacción y de acceder a derechos y oportunidades (ONU-Hábitat, 2015). En ese sentido, el acceso se define como la habilidad de alcanzar bienes, servicios y actividades deseados, por lo que la diferencia con el concepto de movilidad es que la accesibilidad significa la manera cómo estos elementos pueden ser alcanzados (Litman, 2020), es decir, la facilidad para superar una distancia y, por lo tanto, dimensiona la posibilidad de ir de un lugar a otro, en términos de espacio, transporte y aspectos temporales (Miralles-Guasch, 2002).

Los lugares de trabajo con sus respectivos empleos, son una materialización de las oportunidades y como tales, objeto de la accesibilidad. Estos se expresan como el número de empleos o el número de personas dentro de un ámbito espacial de influencia de un puesto de trabajo. Este último aspecto es utilizado en el presente estudio como una medida del alcance que tienen las concentraciones de trabajo o centros de empleo, siendo factible de usar debido a su facilidad de interpretación (Chen et al., 2014).

Al mismo tiempo, con la salida de empleos de la zona central de la ciudad y la creación de nuevos puestos de trabajo fuera de ella, la posibilidad de obtener un empleo disminuye, ya que los trabajadores tendrán que realizar viajes más largos al trabajo o quedar desempleados (Suárez y Delgado, 2007), haciendo relevante las características de conectividad en el espacio urbano.

En términos generales, la conectividad es una cualidad que surge a partir de la existencia de vínculos entre objetos y actividades interrelacionadas, las cuales se representan de forma física como una estructura conformada por una red de corredores, cuya función es mover bienes, servicios, información y personas entre distintos puntos del territorio y sus características dependen de los siguientes aspectos (Figueroa y Rozas, 2005):

- Aspectos físicos estructurales del territorio que significan dificultades o facilidades para desplegar dicha red.

- La organización particular del territorio que exige la conexión de lugares específicos, en función de demandas de tipo social y económica.

Así pues, la conectividad solo se puede dar cuando existe la posibilidad de unir dos lugares y expresa la fricción del espacio, el lugar con la menor fricción con relación a otros lugares es comúnmente el lugar más accesible (Rodrigue et al., 2006).

\subsection{Aproximación desde el análisis de la red de calles}

Desde el punto de vista matemático y topológico, la ciudad está restringida a su mapa, es decir, a la red que conforman sus calles, sin información adicional (Courtat et al., 2012), sin embargo, la red vial puede tener también connotaciones de distintos tipos: sociales, físicas o económicas. Desde el punto de vista social, la calle es el espacio público por excelencia, lugar de encuentro y convivencia; desde el punto de vista económico, es lugar de comercio o de promoción; y desde el punto de vista físico es la red de circulación y tránsito que sirve a los medios de transporte y al ser humano para moverse de un lugar a otro en la ciudad (Bazant, 2008). Con relación a ello, para Porta et al. (2006) las claves del orden de la complejidad de los sistemas en sociología y biología comparten propiedades topológicas similares. Sus estudios han demostrado que esas claves son aplicables a las redes de calles de las ciudades, bajo reglas de jerarquía y adhesiones preferenciales, de forma incrustada a las formas climáticas, geográficas, económicas, sociales y culturales más diversas.

El enfoque adoptado en este artículo, el de la evaluación de centralidad múltiple (MCA por sus siglas en inglés) de Porta et al. (2006), es una metodología de análisis de grafo primario o directo de centralidades del sistema de vialidades urbanas. La MCA responde al efecto de las localizaciones centrales en la estructura de la red en términos de cercanía, de intermediación y de relevancia.

ACE, 16 (47) CC BY-ND 3.0 ES | UPC Barcelona, España | Accesibilidad urbana y conectividad de los centros de empleo en Culiacán. DOI: http://dx.doi.org/10.5821/ace.16.47.9694 
Adicional a estos aspectos, se adopta una medida de centralidad basada en la influencia que tiene una localización para el resto de la red. En general, las medidas de centralidad utilizadas se definen así:

- $\quad$ Centralidad por cercanía. Está basado en el concepto de la mínima distancia entre dos nodos.

- Grado de centralidad. Se basa en la importancia que poseen los nodos cuando están enlazados a la mayor cantidad de otros nodos en la red.

- Centralidad por intermediación. Es la propiedad de nodos intermedios que pueden influir en la interacción entre nodos no adyacentes.

- Centralidad "eigenvector". Propuesto por Bonacich (1987), mide la influencia de un nodo de una red por la importancia de sus conexiones, es decir, que está conectado a su vez con otros nodos de centralidad significativa.

Analizar la accesibilidad con base en las propiedades de centralidad de la red, midiendo la conectividad entre los distintos puntos del espacio urbano y utilizando la atracción de los lugares de trabajo concentrados como centros de empleo, permite conseguir una noción de accesibilidad abarcando los componentes de uso de suelo, infraestructura, tiempo y un segmento de la población definida por su condición laboral.

\section{4. Ámbito de estudio y datos}

La ciudad de Culiacán Rosales (en adelante Culiacán) es la capital del Estado de Sinaloa, ubicado en el noroeste de México. Culiacán tiene características particulares fisiográficas como ríos, arroyos y lomas, así como infraestructura férrea e hidroagrícola. Al respecto, la ciudad es atravesada por dos ríos que confluyen en el centro de la ciudad, dando origen a un tercer cuerpo de agua: los ríos Humaya, Tamazula y Culiacán, respectivamente. Por otro lado, según el censo del año 2010 (INEGI, 2010), Culiacán contaba con 675,773 habitantes y una densidad de 136 viviendas/hectárea. Así mismo, se trata de una ciudad media que, presenta un crecimiento expansivo hacia las periferias y una estructura vial de forma radial, producto de un modelo de brazos en forma de estrella en torno a corredores de transporte, pero debido a las características mencionadas, la continuidad de las vialidades entre distintos sectores no se mantiene (CODESIN; MAPASIN, 2016).

Los datos necesarios para el análisis de la accesibilidad y conectividad con base en medidas de centralidad de la red y la concentración de empleos son: el grafo primario de las vialidades del caso de estudio, los lugares de trabajo localizados (en adelante LTL) y la ubicación de la población ocupada. La población total y la ocupada se obtuvieron del último censo realizado por el INEGI (2010) y los LTL se retomaron del Directorio Estadístico Nacional de Unidades Económicas (DENUE) del año 2019 (INEGI, 2019), organizados en áreas geoestadísticas básicas (en adelante AGEB) definidas por el INEGI. En lo relativo a este estudio, el área urbana de Culiacán abarca $140.12 \mathrm{~km}^{2}$ y se divide en 551 AGEB (Figura 1).

Para el cálculo de la población que potencialmente puede acceder a los centros de empleo, se requiere definir un área de influencia a partir de éstos con base en las características de movilidad por motivo de trabajo, como el origen y destino, medios de transporte y tiempo utilizados en los traslados. Sin embargo, debido a que los estudios de origen y destino sobre desplazamientos cotidianos en Culiacán tienen distintas metodologías y niveles de desagregación, así como una antigüedad de al menos diez años (2006 y 2010), se considera que difícilmente responden a la situación actual del caso. Ante esa situación, se tiene como alternativa utilizar la Encuesta Intercensal del año 2015 realizada por el INEGI que, por primera vez abordó la temática de la movilidad cotidiana como tal, enfocándose en los aspectos educativos y laborales. Para los aspectos laborales o desplazamientos por motivo de trabajo se tiene información de la población ocupada de 12 años y

ACE, 16 (47) CC BY-ND 3.0 ES | UPC Barcelona, España | Accesibilidad urbana y conectividad de los centros de empleo en Culiacán. DOI: http://dx.doi.org/10.5821/ace.16.47.9694 
más de edad, desde su lugar de residencia hasta su lugar de trabajo. No obstante, el nivel de desagregación no se presenta por AGEB, por lo que aun cuando no se tienen los orígenes y destinos de los viajes a ese nivel, sí se puede saber si el destino se encuentra en la localidad de origen, en qué medio o combinación de medios de transporte se realizaron y cuánto tiempo duraron.

Figura 1. Ámbito de estudio

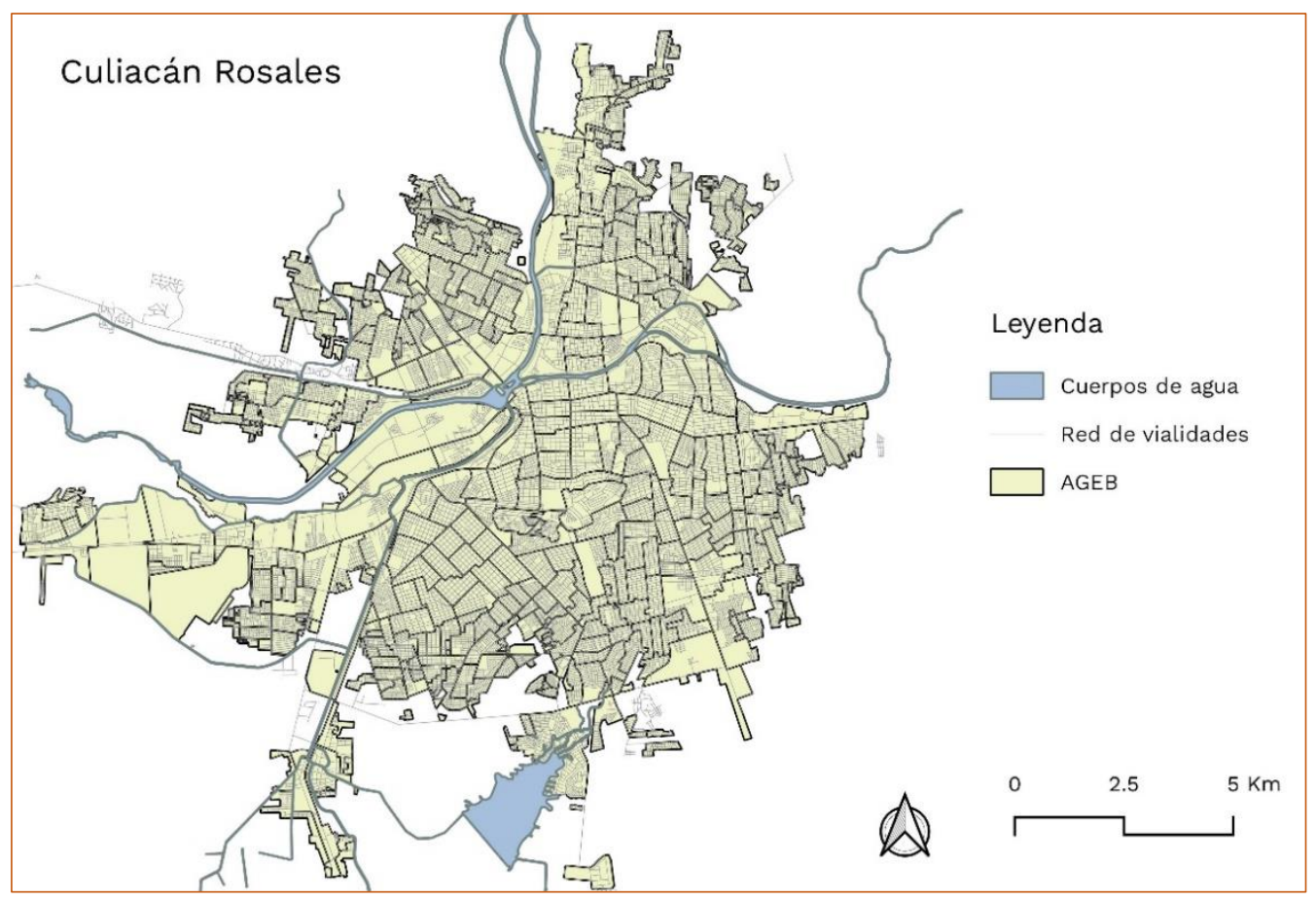

Fuente: Elaboración propia a partir de los datos del Marco Geoestadístico de INEGI (2019).

Para procesar dicha información en un sistema de información geográfica, se requiere la cartografía geoestadística y del grafo primario que conforma la estructura de calles de la ciudad (segmentos e intersecciones de calles), las cuales se obtuvieron del Marco Geoestadístico del INEGI del año 2019 (INEGI, 2019).

\section{Caracterización de los centros de empleo}

El centro de Culiacán, dominado por el comercio sobre cualquier otro uso de suelo, es un lugar de intensa actividad humana, empleo, transacciones y viajes a todos los puntos de la ciudad y desde cualquier otro punto al centro. En el centro se encuentran también centros educativos, culturales, de salud y asistencia pública, recreación y deporte, así como de administración, convirtiéndose en la zona de mayor influencia en la ciudad y que ha generado dependencia en las actividades diarias de un sector importante de la población de Culiacán. No obstante, con base en una comparación de los datos del DENUE de 2010 y 2019, se puede detectar que la ubicación del empleo ha tenido un cambio en los últimos diez años, al haber aparecido más unidades económicas en zonas distintas al centro. Inclusive, se puede observar que la densidad de población es mayor hacia la periferia de la ciudad, alejándose de la parte central y de la zona de confluencia de los ríos (Figura 2). Por su parte, en Culiacán la población económicamente activa es de 300,701 personas, de las cuales 291,381 están ocupadas (INEGI, 2010).

ACE, 16 (47) CC BY-ND 3.0 ES | UPC Barcelona, España | Accesibilidad urbana y conectividad de los centros de empleo en Culiacán. DOI: http://dx.doi.org/10.5821/ace.16.47.9694 
Figura 2. Densidad de población por AGEB

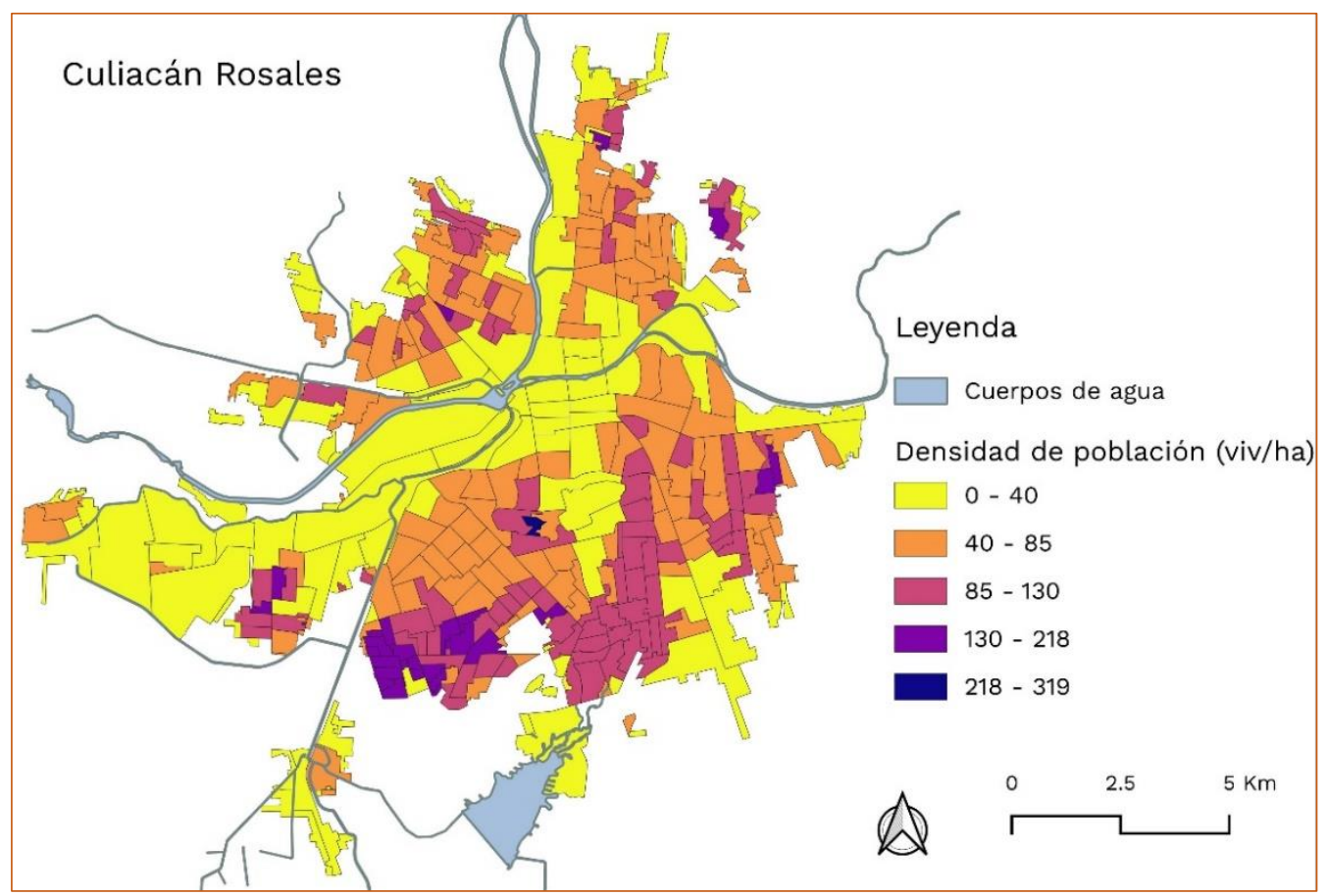

Fuente: Elaboración propia a partir de datos del Censo de 2010 (INEGI, 2010).

En cuanto a la identificación de los centros de empleo, se retoman los estudios de detección de subcentros de empleo en áreas urbanas policéntricas (recuperados también por autores como Aguirre y Marmolejo, 2010 y Ruiz et al., 2012), que originalmente consideran la densidad laboral $\left(\mathrm{LTL} / \mathrm{Km}^{2}\right)$ con base en el destino de los viajes con motivo de trabajo para identificar subcentros metropolitanos, en este caso con el objetivo de detectar la concentración significativa de empleos en el ámbito espacial de una ciudad monocéntrica. Pero, al carecer de datos actuales y precisos de origen y destino de los viajes de trabajo, como se ha explicado, los lugares de trabajo localizados se obtuvieron del DENUE (INEGI, 2019), que contabiliza por rangos el personal ocupado de las unidades económicas en cada una de las AGEB. Así, con dicha información, se aplicaron tres criterios correspondientes a dos metodologías de detección de subcentros diferentes: picos de densidad de empleo en zonas contiguas (McDonald y McMillen, 1990) con el criterio de identificación de picos de densidad mediante SIG; y umbrales (Giuliano y Small, 1991; García-López, 2007) con los criterios de una densidad de empleo mayor a 2500 empleos $/ \mathrm{Km}^{2}$ y de densidad mayor a la media del sistema.

Con base en los datos analizados, las AGEB presentaron un total de 295,077 puestos de trabajo ocupados y una densidad laboral media de 1,808.6 LTL/ $\mathrm{Km}^{2}$. A partir de la aplicación de los criterios mencionados se identificaron 72 AGEB como centros de empleo, con una densidad laboral mínima de 2965 LTL/ $/ \mathrm{Km}^{2}$. Para efectos de análisis de estas áreas como elementos de la red, se calculó el centro geométrico de cada una de estas AGEB y se reubicaron sobre la vialidad principal más cercana. En algunos casos de adyacencia se utilizó un solo punto para conformar un solo centro de empleo (CE). Como resultado se obtuvieron 54 centros de empleo con distintas características de ubicación en la ciudad: 1) centro, 2) contiguo al centro (sin haber una separación espacial de la zona centro) y 3) subcentro (debido a que presenta una separación espacial de las dos primeras y que se ubica mayormente en la periferia urbana). Como resultado, la mayoría de los centros de empleo se ubican fuera del centro urbano, pero con menores densidades laborales (Tabla 1 y Figura 3).

ACE, 16 (47) CC BY-ND 3.0 ES | UPC Barcelona, España | Accesibilidad urbana y conectividad de los centros de empleo en Culiacán. DOI: http://dx.doi.org/10.5821/ace.16.47.9694 
Tabla 1. Centros de empleo de Culiacán

\begin{tabular}{|c|c|c|c|c|c|}
\hline Número & Tipo de ubicación & $\begin{array}{l}\text { Densidad laboral } \\
\left(\mathrm{LTL} / \mathrm{Km}^{2}\right)\end{array}$ & Número & Tipo de ubicación & $\begin{array}{l}\text { Densidad laboral } \\
\left(\mathrm{LTL} / \mathrm{Km}^{2}\right)\end{array}$ \\
\hline 5 & Centro & 15940.23 & 43 & Contiguo & 3610.95 \\
\hline 6 & Centro & 15025.11 & 45 & Contiguo & 4259.18 \\
\hline 10 & Centro & 16212.78 & 46 & Contiguo & 3056.77 \\
\hline 11 & Centro & 22336.05 & 47 & Contiguo & 3088.91 \\
\hline 16 & Centro & 24964.82 & 1 & Subcentro & 6250.00 \\
\hline 29 & Centro & 10428.19 & 2 & Subcentro & 6896.55 \\
\hline 38 & Centro & 12105.26 & 3 & Subcentro & 3902.44 \\
\hline 39 & Centro & 10067.45 & 4 & Subcentro & 3578.90 \\
\hline 40 & Centro & 14266.44 & 7 & Subcentro & 6390.69 \\
\hline 44 & Centro & 9185.86 & 8 & Subcentro & 3389.83 \\
\hline 12 & Contiguo & 4045.10 & 9 & Subcentro & 2966.51 \\
\hline 13 & Contiguo & 6291.45 & 14 & Subcentro & 5253.73 \\
\hline 15 & Contiguo & 4857.40 & 19 & Subcentro & 3469.91 \\
\hline 17 & Contiguo & 3043.25 & 20 & Subcentro & 4346.76 \\
\hline 18 & Contiguo & 3972.33 & 21 & Subcentro & 4649.63 \\
\hline 25 & Contiguo & 3254.57 & 22 & Subcentro & 5234.90 \\
\hline 26 & Contiguo & 8128.81 & 23 & Subcentro & 9044.82 \\
\hline 27 & Contiguo & 3137.48 & 24 & Subcentro & 2965.52 \\
\hline 28 & Contiguo & 3938.25 & 34 & Subcentro & 4049.61 \\
\hline 30 & Contiguo & 4266.55 & 37 & Subcentro & 3944.95 \\
\hline 31 & Contiguo & 5405.89 & 48 & Subcentro & 19411.76 \\
\hline 32 & Contiguo & 3577.02 & 49 & Subcentro & 3033.71 \\
\hline 33 & Contiguo & 3650.42 & 50 & Subcentro & 3615.16 \\
\hline 35 & Contiguo & 4247.36 & 51 & Subcentro & 3543.78 \\
\hline 36 & Contiguo & 3323.18 & 52 & Subcentro & 3600.87 \\
\hline 41 & Contiguo & 3565.54 & 53 & Subcentro & 9734.51 \\
\hline 42 & Contiguo & 3827.98 & 54 & Subcentro & 5104.76 \\
\hline
\end{tabular}

Fuente: Elaboración propia.

Figura 3. Densidad laboral por AGEB y centros de empleo

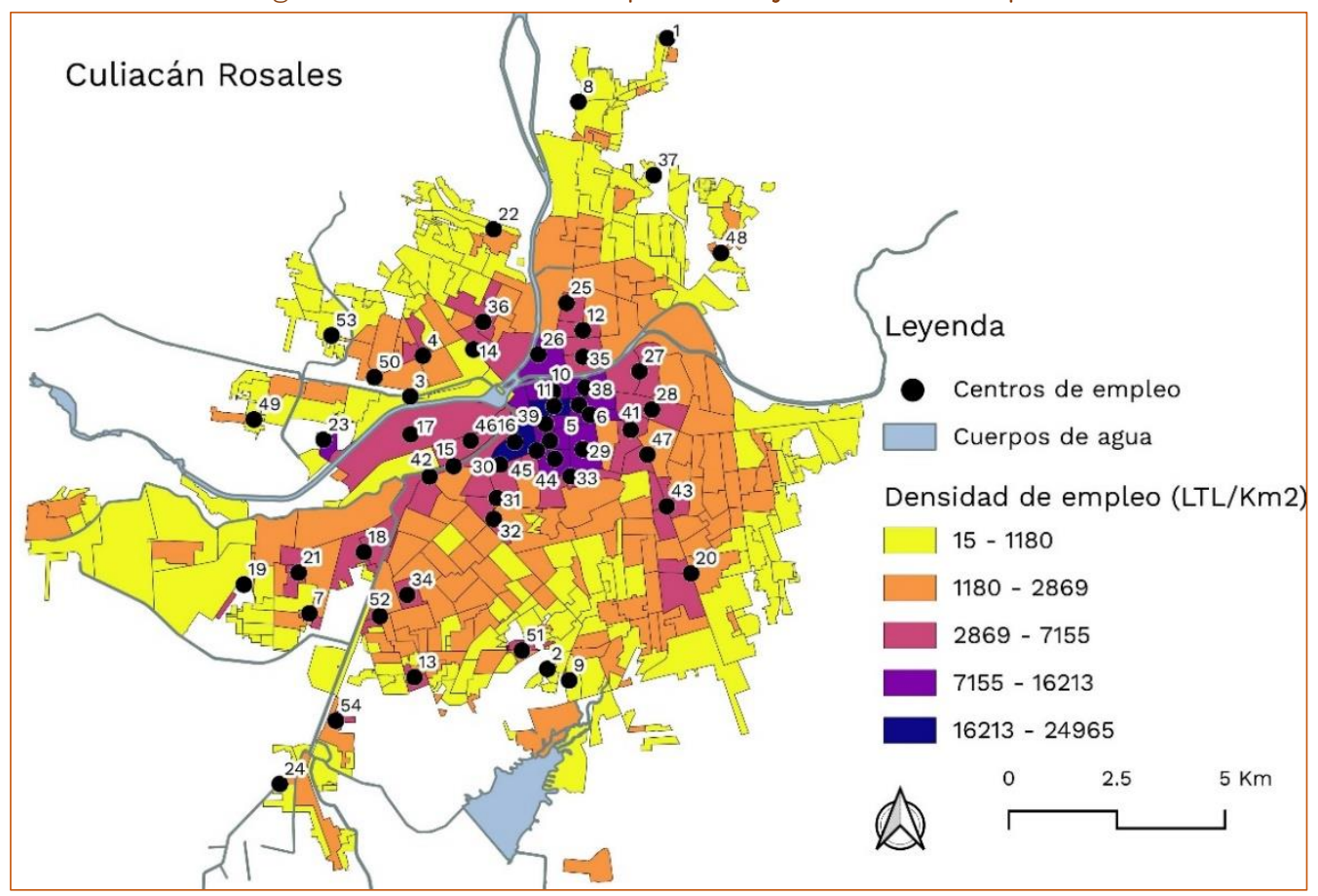

Fuente: Elaboración propia a partir de los datos del DENUE de INEGI (2019).

ACE, 16 (47) CC BY-ND 3.0 ES | UPC Barcelona, España | Accesibilidad urbana y conectividad de los centros de empleo en Culiacán. DOI: $\underline{\text { http://dx.doi.org/10.5821/ace.16.47.9694 }}$ 
Con respecto a los viajes por motivo laboral en Culiacán, se puede decir que en un día común se realizan 302,143 desplazamientos, de los cuales el 97.6\% comienzan y terminan dentro del municipio, según datos de INEGI (2015). De este último segmento de viajes, el $82.2 \%$ se realiza en transporte motorizado, ya sea vehículo particular, transporte público o transporte laboral, en tanto que el 8.9\% se realiza en medios no motorizados (INEGI, 2015) (ver Tabla 2).

Tabla 2. Reparto modal de viajes por motivo de trabajo

\begin{tabular}{|l|r|}
\hline Modo de transporte & $\begin{array}{l}\text { Porcentaje de viajes por motivo de } \\
\text { trabajo }\end{array}$ \\
\hline Vehículo particular (automóvil, camioneta o motocicleta) & \\
\hline Transporte público (camión, taxi, combi o colectivo) & \\
\hline Caminar & \\
\hline Transporte laboral & $36.1 \%$ \\
\hline Bicicleta & $7.6 \%$ \\
\hline No se especifica & $3.4 \%$ \\
\hline Fuente: Elaboración propia con base en INEGI (2015). & \\
\hline
\end{tabular}

Referente a estos desplazamientos, los tiempos de viaje se distribuyen, de menor a mayor duración en: $29.0 \%$ hasta 15 minutos, $19.2 \%$ de 16 a 30 minutos, 37.5\% de 31 minutos a 1 hora, 2.8\% más de 1 hora y hasta 2 horas, mientras que el $5.6 \%$ no puede determinarlo y el 5.3\% no se traslada (INEGI, 2015). A partir de los datos de todos los viajes por motivo de trabajo en cualquier medio de transporte, se tiene que la duración promedio de traslado, es de 25 minutos. Si además se considera una velocidad de tránsito promedio de $14.77 \mathrm{Km} / \mathrm{Hr}$, en hora pico, para el caso de la ciudad de Culiacán (Sin Tráfico, 2017), se tendría una distancia de $6.28 \mathrm{~km}$ factible de recorrer en esos 25 minutos, considerándolos un tiempo y una distancia razonable, que la mayoría estaría dispuesta a emplear y recorrer, respectivamente, para ir al trabajo, principalmente en transporte público o privado.

\section{Análisis de la accesibilidad urbana y la conectividad de los centros de empleo}

Para la medición de la centralidad de la red, se realizó el cómputo en el software de sistema de información geográfica QGIS con herramientas de procesamiento vectorial de GRASS, específicamente la herramienta de v.net.centrality. De forma operativa, cada una de las medidas de centralidad consideradas determinan lo siguiente:

- Centralidad por intermediación $\left(C^{b}\right)$. Mide el número mínimo de transferencias que reciben los nodos en los recorridos de la red. Toma valores entre 0 y 1, acercándose a 1 cuando el nodo interviene en un mayor número de líneas geodésicas.

- Centralidad por cercanía (C). Mide el valor de la distancia recorrida de un nodo a otro.

- Grado de centralidad $\left(C^{D}\right)$. Asume valores entre 0 y 1, siendo más cercano a 1 cuando está conectado a un mayor número de nodos de la red.

- Centralidad "eigenvector" $\left(C^{\natural}\right)$. Mide la disminución de la eficiencia de la red si el nodo fuese removido de la red.

Cada una de estas medidas fue aplicada a la totalidad de la red de calles de la ciudad de Culiacán. Luego, para cada centro de empleo, se determinó un área de servicio como una sección de la red delimitada por el recorrido de todas las rutas posibles hasta una distancia de $6.28 \mathrm{Km}$ a partir del centro geométrico (Figura 4 como ejemplo del CE número 50). Así, se cuantificaron los nodos y sus características, así como la población ocupada dentro de cada área de servicio de los CE, para conocer bajo qué condiciones de centralidad de la red se encuentran los centros de empleo y a cuántas personas les resultaría accesible.

ACE, 16 (47) CC BY-ND 3.0 ES | UPC Barcelona, España | Accesibilidad urbana y conectividad de los centros de 10 empleo en Culiacán. DOI: http://dx.doi.org/10.5821/ace.16.47.9694 
Figura 4. Área de servicio del centro de empleo no. 50

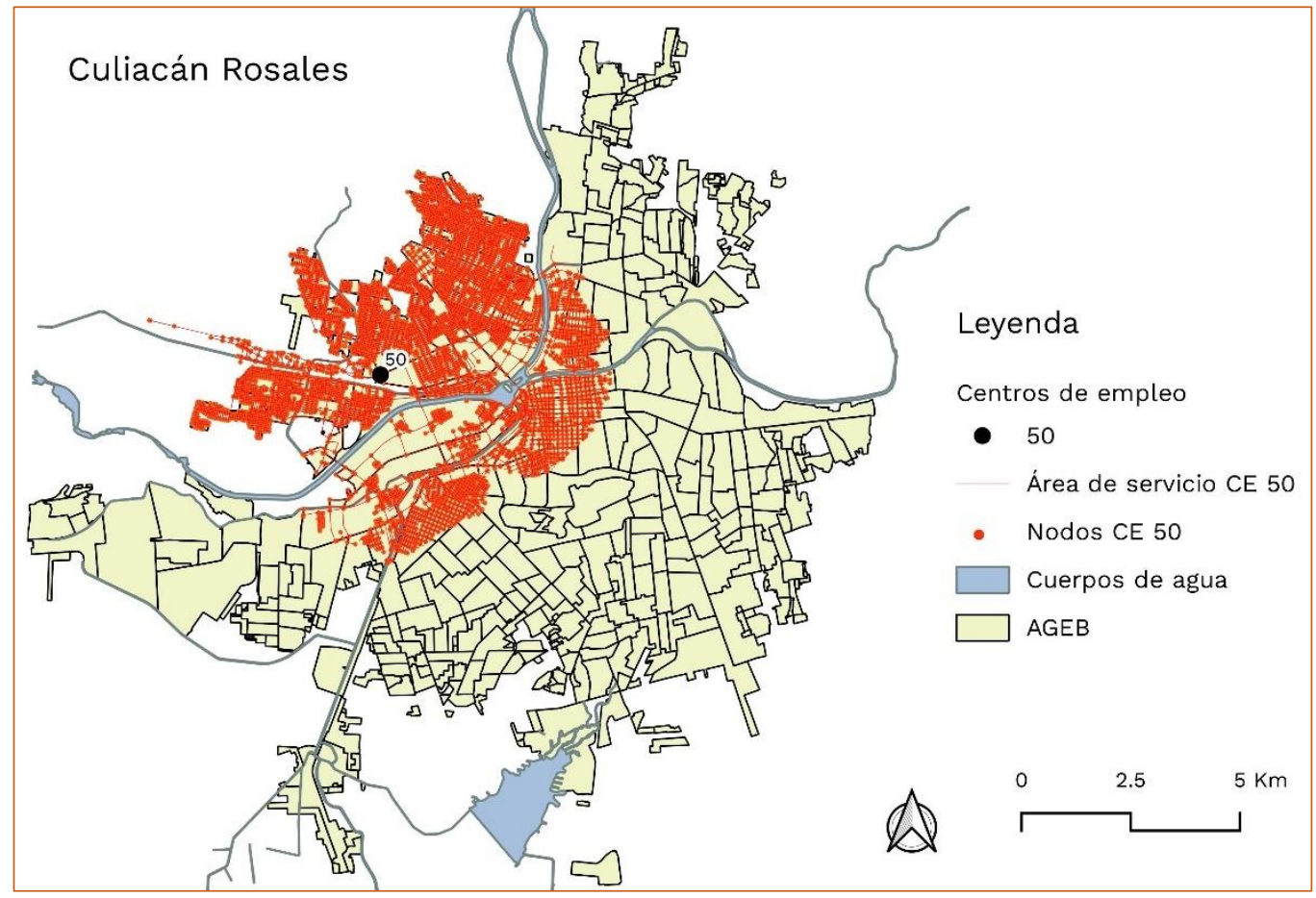

Fuente: Elaboración propia a partir del Marco Geoestadístico de INEGI (INEGI, 2019).

Figura 5. Centralidad de la red de calles por cercanía ( $\left.C^{C}\right)$

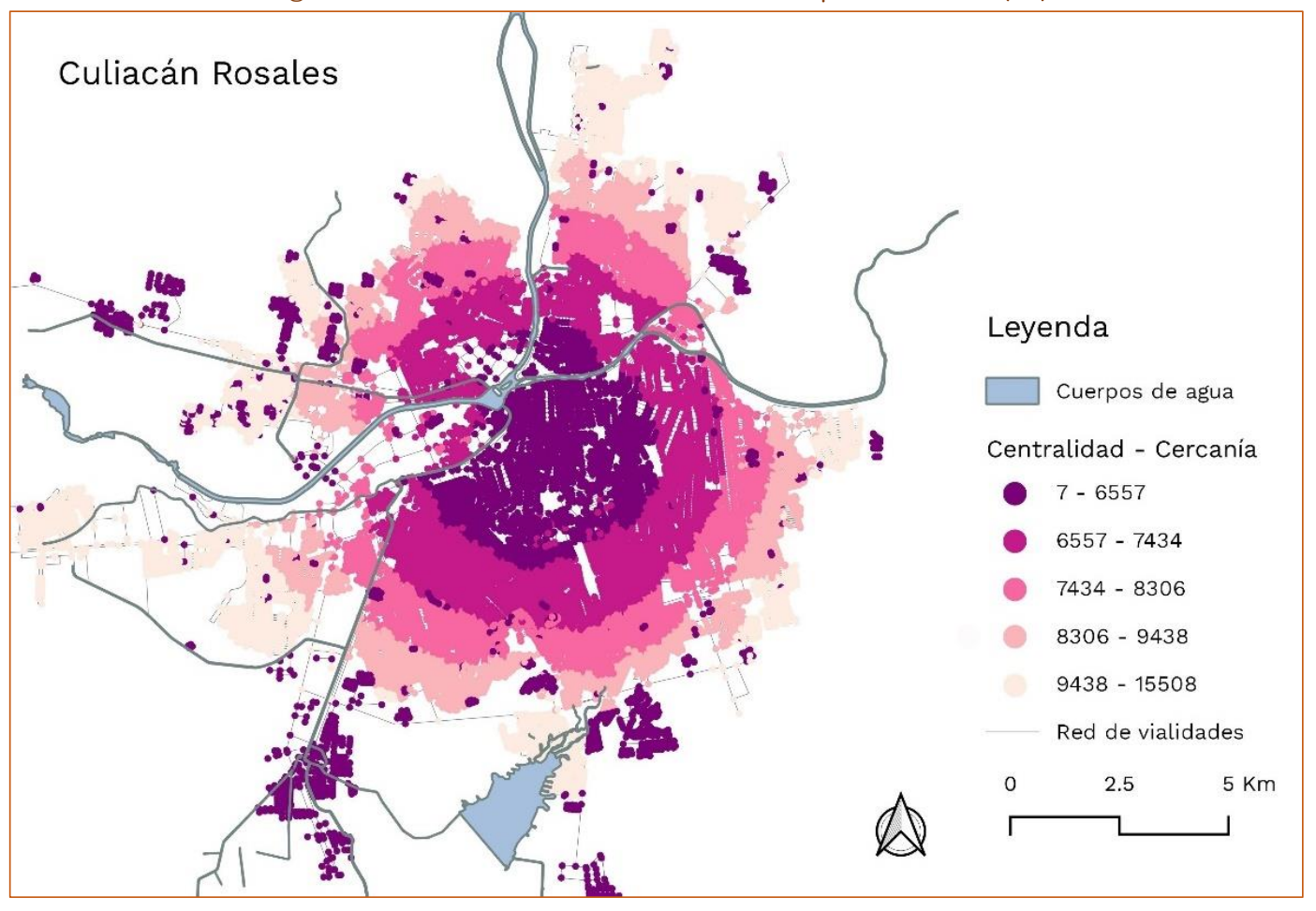

Fuente: Elaboración propia a partir del Marco Geoestadístico de INEGI (INEGI, 2019).

ACE, 16 (47) CC BY-ND 3.0 ES | UPC Barcelona, España | Accesibilidad urbana y conectividad de los centros de empleo en Culiacán. DOI: http://dx.doi.org/10.5821/ace.16.47.9694 
Después de los cómputos y cálculos, se obtiene una visión global de las características de centralidad de la ciudad. Con ello, se tiene que las medidas de centralidad por cercanía, por intermediación y "eigenvector" revelan a la vista resultados interesantes para la ciudad en general. Al mismo tiempo, las medidas de intermediación y grado de centralidad resultaron tener el potencial de caracterizar más detalladamente las secciones de red de las áreas de servicio de los centros de empleo.

Con $C^{C}$ el área urbana de Culiacán se secciona en anillos concéntricos (Figura 5) en que los centros de empleo, en la mayoría de los casos, reafirmarían su tipo de ubicación. En este sentido los CE de la zona centro se ubican todos dentro del primer contorno de $C^{c}$, los CE contiguos se ubican entre la zona central y el tercer anillo y, por su parte, los CE subcentro se ubican entre el segundo y quinto anillo (ver Tabla 3), puesto que estos CE se determinaron no por su lejanía al centro sino por su separación espacial. Así, con base en el rango de $C^{c}$, hay subcentros con mayor centralidad que otros.

Por su parte, los resultados de $C^{B}$ a nivel general revelan que los mayores valores (>0.0053) se ubican conectados en la misma línea de los ejes de las vialidades más relevantes de la ciudad, consideradas así por su longitud y percepción de conectividad (ver Figura 6). Estas vialidades principales fueron proyectadas y materializadas en distintas épocas del crecimiento de Culiacán, desde el centro urbano, que también es el Centro Histórico, hasta los libramientos de la ciudad y vías de acceso a las áreas de más reciente urbanización y, con el presente análisis, su carácter vertebrador de subredes para las nuevas áreas urbanas queda ahora cuantitativamente manifiesto.

Figura 6. Centralidad de la red de calles por intermediación $\left(C^{\natural}\right)$

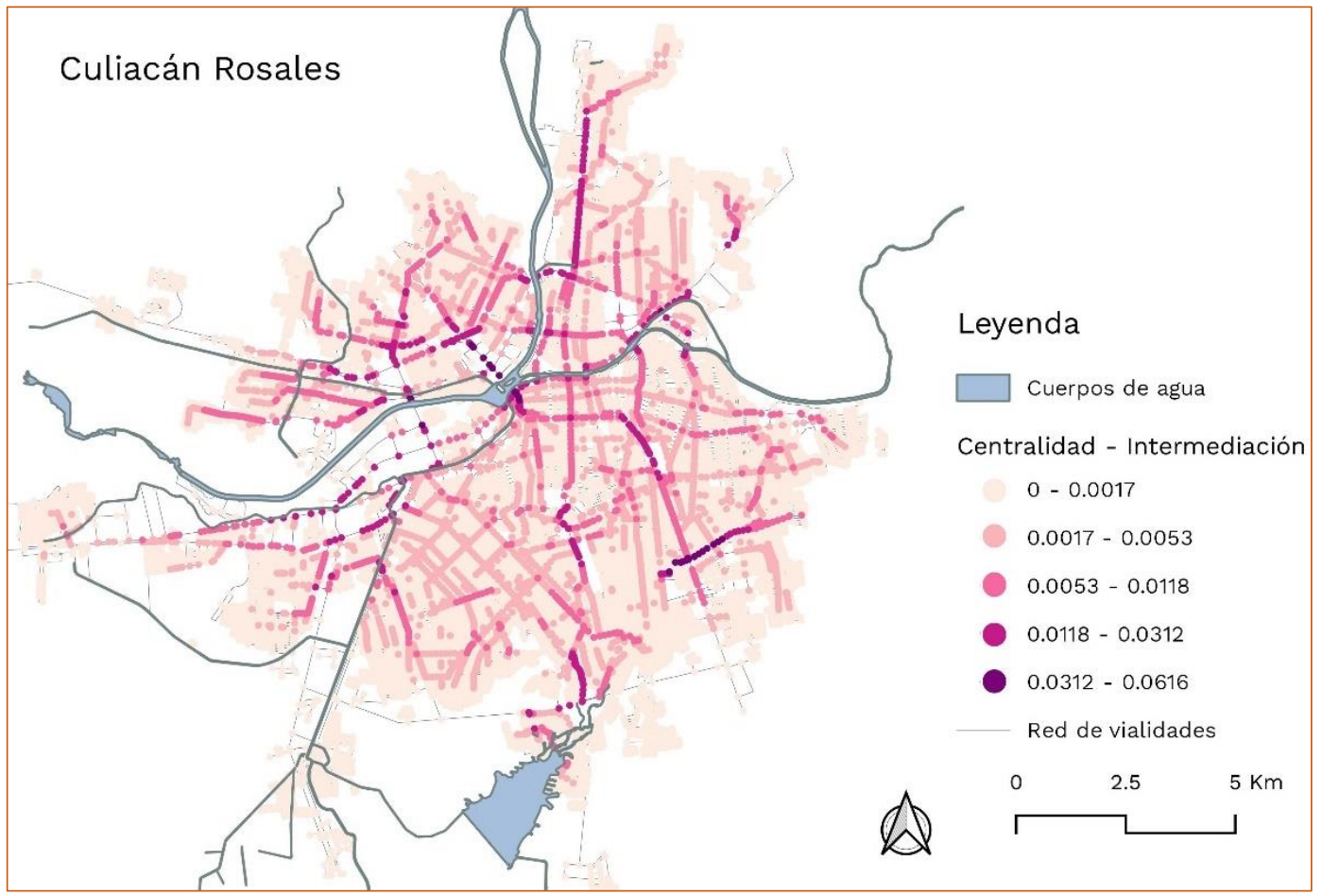

Fuente: Elaboración propia a partir del Marco Geoestadístico de INEGI (INEGI, 2019).

Al mismo tiempo, con base en un análisis a escala de las secciones de red del área de servicio de los $\mathrm{CE}$, se encontró que la cantidad de nodos con los mayores valores de $C^{B}(>0.0053)$ y $C^{D}(>0.00013)$ están relacionados de forma tal que cuando la cantidad de una aumenta, la otra también lo hace y viceversa. A partir de ello, se entiende que ambos tipos de centralidades comunican el mismo grado de accesibilidad, pero la medida $C^{B}$ para una centralidad lineal y la medida $C^{D}$ para una centralidad

ACE, 16 (47) CC BY-ND 3.0 ES | UPC Barcelona, España | Accesibilidad urbana y conectividad de los centros de 12 empleo en Culiacán. DOI: http://dx.doi.org/10.5821/ace.16.47.9694 
puntual (Figura 7). Por su parte, las áreas de servicio de los CE ubicadas en el centro abarcan la mayor cantidad de nodos de valores altos, debido a la estructura monocéntrica dominante de la ciudad, presentando una disminución de la cantidad de nodos cuanto más se aleje del centro (Tabla 3).

En lo que respecta a la cantidad de personas que podría tener una accesibilidad potencial a los diferentes CE, esta cifra también se relaciona con el tipo de CE, siendo los de tipo subcentro los que menos habitantes y población ocupada podrían atender (ver Tabla 3). No obstante, es de notar que la accesibilidad a los CE de cualquier tipo por otros motivos de viaje relacionados con la diversidad de actividades disponibles, podría ser mayor. En este marco, se refuerza el peso de la monocentralidad en la accesibilidad urbana, en el ámbito laboral y para el resto de los ámbitos que motivan otros viajes relacionados con las actividades en las que se desarrollan dichos empleos.

Figura 7. Grado de centralidad de la red de calles ( $\left.C^{D}\right)$

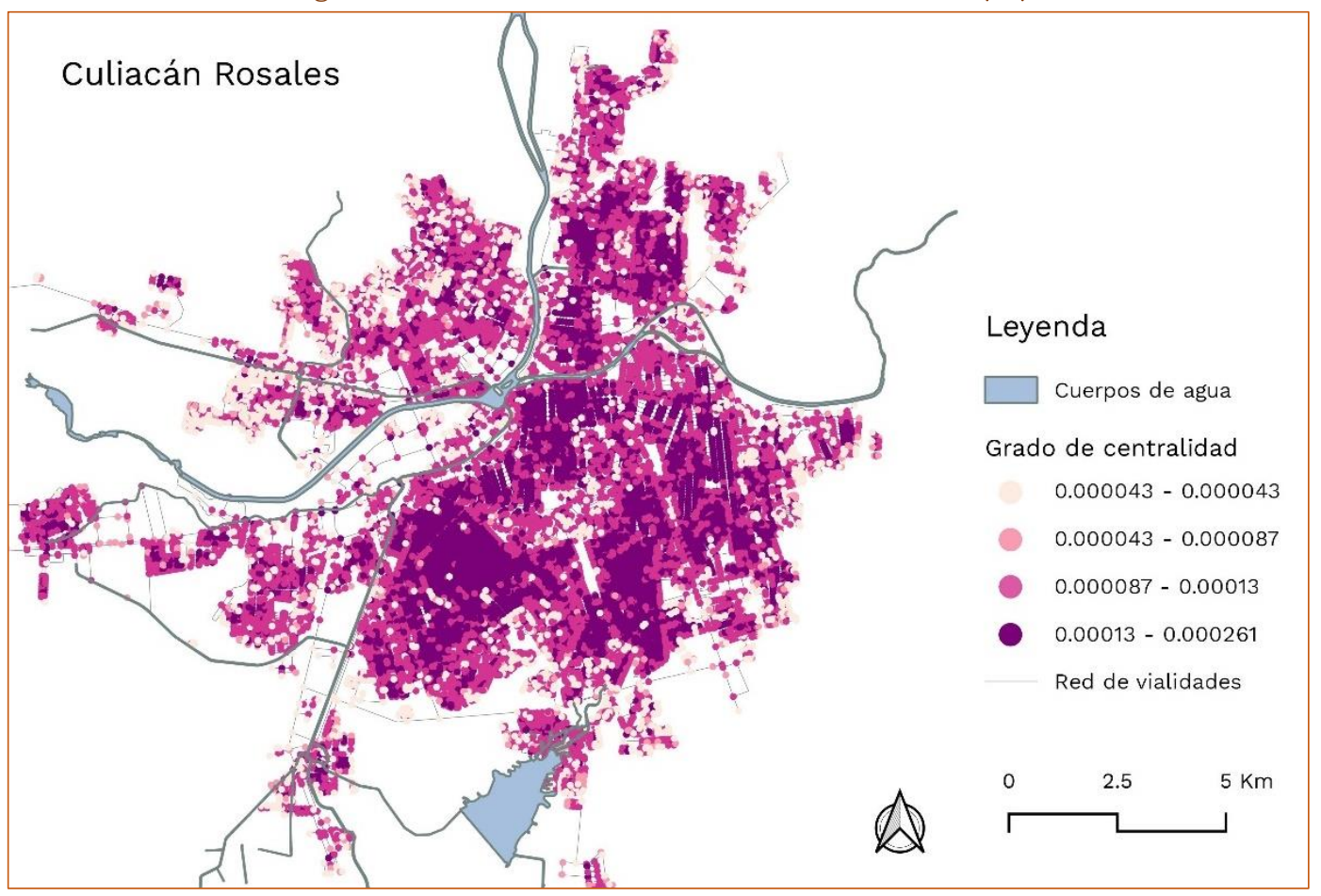

Fuente: Elaboración propia a partir del Marco Geoestadístico de INEGI (INEGI, 2019).

Tabla 3. Aproximación a la accesibilidad urbana por tipo de centro de empleo

\begin{tabular}{|l|l|l|l|}
\hline Aproximación a la accesibilidad urbana & Centro & Contiguo & Subcentro \\
\hline $\begin{array}{l}\text { Ubicación de los CE con respecto a los valores de } \\
\text { centralidad por cercanía }\end{array}$ & $\begin{array}{l}\text { Primera } \\
\text { circunferencia }\end{array}$ & Anillos 1 al 3 & Anillos 2 al 5 \\
\hline $\begin{array}{l}\text { Cantidad media de nodos en el área de servicio con } \\
\text { valor de grado de centralidad >0.00013 }\end{array}$ & $10,803.7$ nodos & $8,938.42$ nodos & $4,311.21$ nodos \\
\hline $\begin{array}{l}\text { Cantidad media de nodos en el área de servicio con } \\
\text { valor de centralidad por intermediación >0.0053 }\end{array}$ & $1,041.2$ nodos & 848.62 nodos & 374.13 nodos \\
\hline $\begin{array}{l}\text { Cantidad media de población con acceso potencial a } \\
\text { CE en el tiempo medio razonable en transporte } \\
\text { motorizado. }\end{array}$ & $\begin{array}{l}497,138 \\
\text { personas }\end{array}$ & $\begin{array}{l}404,314 \\
\text { personas }\end{array}$ & personas \\
\hline $\begin{array}{l}\text { Cantidad media de población ocupada con acceso } \\
\text { potencial a CE en el tiempo medio razonable en } \\
\text { transporte motorizado. }\end{array}$ & $\begin{array}{l}212,042 \\
\text { personas }\end{array}$ & $\begin{array}{l}173,118 \\
\text { personas }\end{array}$ \\
\hline $\begin{array}{l}\text { Funsonas } \\
\text { personas }\end{array}$
\end{tabular}

Fuente: Elaboración propia.

ACE, 16 (47) CC BY-ND 3.0 ES | UPC Barcelona, España | Accesibilidad urbana y conectividad de los centros de empleo en Culiacán. DOI: http://dx.doi.org/10.5821/ace.16.47.9694 
Por último, la aplicación de la centralidad "eigenvector"(Figura 8) permite observar que los nodos de mayor influencia resultantes están presentes en las AGEB con mayor densidad laboral y con mayor cantidad de unidades económicas, ya que, de un total de 560 nodos con una influencia importante, 307 están presentes en dichas AGEB (54.82\%). Cabe decir que, esta distribución de nodos con altos valores de $C^{E}$ sigue la forma de los principales cuerpos de agua de Culiacán, mismos que para la movilidad cotidiana, principalmente en medios de transporte no motorizados, representan importantes barreras físicas que tienen que ser superadas a través de los puentes que, de acuerdo con los resultados de $C^{B}$, cuentan con los mayores valores de intermediación en toda la ciudad. Se tendría pues, una accesibilidad vulnerable en las áreas donde se ubican los mayores valores de "eigenvector", dado que también se trata de las AGEB con menos habitantes.

Figura 8. Centralidad de la red por "eigenvector" $\left(C^{\ddagger}\right)$

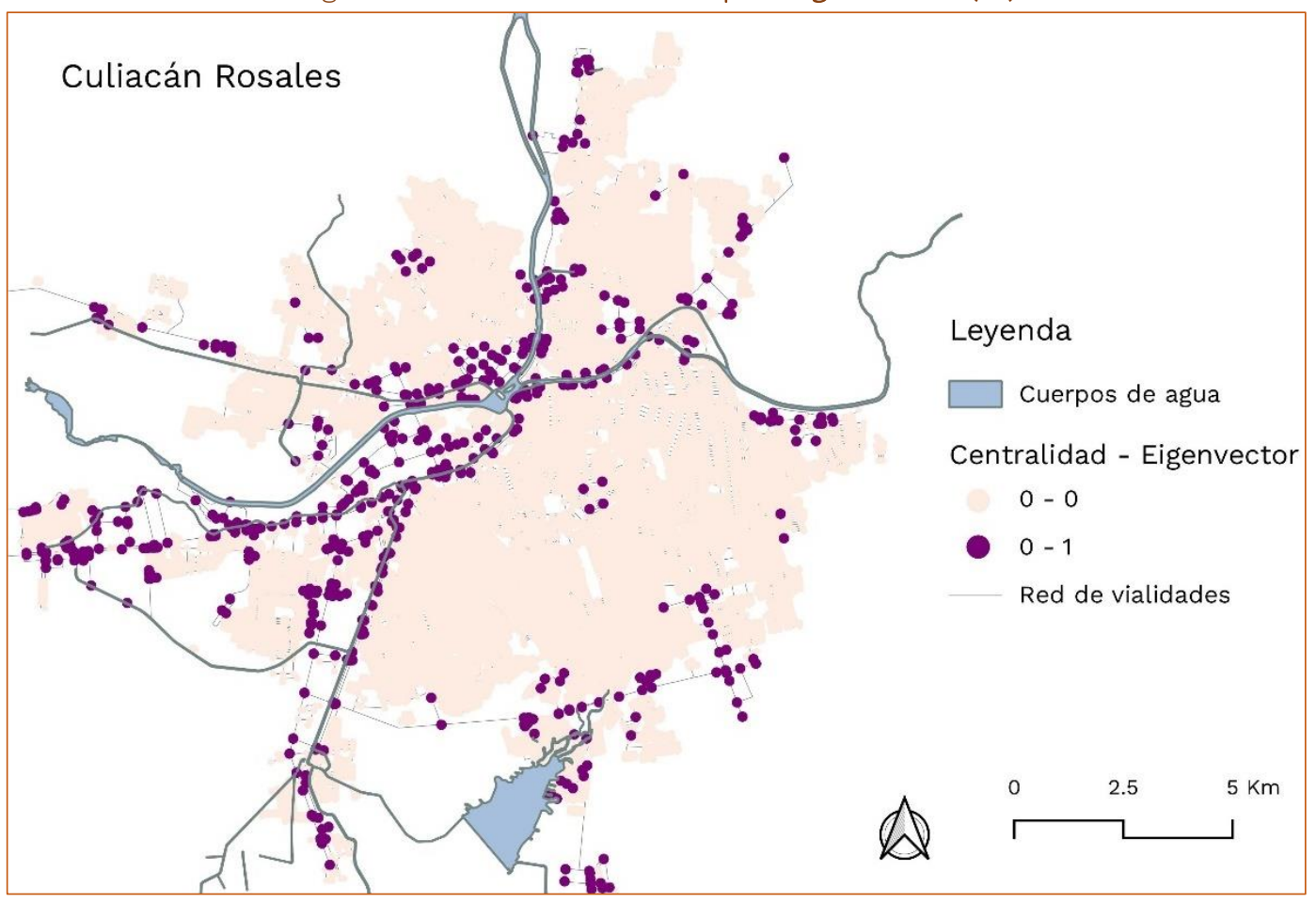

Fuente: Elaboración propia a partir del Marco Geoestadístico de INEGI (INEGI, 2019).

\section{Conclusiones}

Como resultado de una reflexión desde los aspectos teóricos y los resultados del análisis, se puede decir que la fuerza de la monocentralidad en Culiacán no se manifiesta solamente por a la concentración de empleos y accesibilidad urbana, sino también por la población que puede servir, ya sea por la proporción de oportunidades de trabajo o por la conectividad de la red, esta última expresada por las diferentes formas de centralidad.

En función de lo presentado, se cumple con una de las condiciones de accesibilidad urbana propuesta por Geurs (2006): si el número de oportunidades para una actividad aumenta en cualquier lugar, la accesibilidad a esa actividad debería aumentar desde cualquier lugar y viceversa al disminuir las oportunidades.

ACE, 16 (47) CC BY-ND 3.0 ES | UPC Barcelona, España | Accesibilidad urbana y conectividad de los centros de empleo en Culiacán. DOI: $\underline{\text { http://dx.doi.org/10.5821/ace.16.47.9694 }}$ 
Por lo que se refiere a las medidas de centralidad utilizadas, éstas junto con variables de uso de suelo se pueden aplicar también en la identificación de los elementos más fuertes de la red y luego emularlos en la práctica para conseguir una movilidad de trayectos más cortos y eficientes, disminuyendo las emisiones contaminantes del transporte motorizado. De la misma forma, las fortalezas de la red servirían en la implementación de andadores y ciclovías, o en la identificación de mejores rutas para el transporte público, así como puntos de enlace e intercambio estratégicos, por ejemplo.

Por otra parte, ante la falta de información actualizada de desplazamientos cotidianos, no se puede permitir dejar de usar las herramientas disponibles para estudiar la accesibilidad urbana. En este sentido, el método presentado en este artículo pretende acercarse al conocimiento y entendimiento de la accesibilidad potencial complementaria a las medidas de centralidad de la red de calles para todos los medios de transporte, abarcando los componentes de uso de suelo y tiempo empleado para los desplazamientos al trabajo.

Así pues, numerosas líneas de investigación se abren, para que esta aproximación metodológica a la accesibilidad urbana pueda reflejar la complejidad de las distintas capas que se mezclan por cada medio de transporte utilizado en la ciudad, para los distintos motivos de viaje y las distintas características colectivas de la sociedad.

Conflicto de intereses: La autora declara que no hay conflicto de intereses.

\section{Bibliografía}

Aguirre, C., y Marmolejo, C. (2010). Hacia un método integrado de identificación de subcentros a escala municipal: un análisis para la Región Metropolitana de Barcelona. ACE: Architecture, City and Environment, 5(14), 99-122. DOI: https://doi.org/10.5821/ace.v5i14.2508

Alonso, W. (1964). Location and land use. Cambridge: Harvard University Press.

Álvarez de la Torre, G. (2017). Morfología y estructura urbana en las ciudades medias mexicanas. Región y Sociedad, 29(68), 153-191. DOI: https://doi.org/10.22198/rys.2017.68.a872

Batty, M. (2013). The new science of cities. Cambridge: MIT Press.

Bazant, J. (2008). Espacios urbanos. Historia, teoría y diseño. Ciudad de México: Limusa.

Bertaud, A. (2004). The spatial organization of cities: deliberate outcome or unforeseen consequence? Berkeley: UC Berkeley. Recuperado de https://escholarship.org/uc/item/5vb4w9wb

Bhat, C., Handy, S., Kockelman, K., Mahmassani, H., Chen, Q., y Weston, L. (2001). Development of an urban accessibility index: literature review. Austin: Center for Transportation Research, University of Texas. Recuperado de https://ctr.utexas.edu/wp-content/uploads/pubs/4938 1.pdf

Boarnet, M., y Crane, R. (2001). Travel by design: the influence of urban form on travel. Nueva York: Oxford University Press.

ACE, 16 (47) CC BY-ND 3.0 ES | UPC Barcelona, España | Accesibilidad urbana y conectividad de los centros de empleo en Culiacán. DOI: http://dx.doi.org/10.5821/ace.16.47.9694 
Bonacich, P. (1987). Power and centrality: a family of measures. American Journal of Sociology 92(5), 1170-1182. Recuperado de https://www.jstor.org/stable/2780000

Burgess, E. (1925). Growth of the city. En R. Park, The City (pp. 47-62). Chicago: The University of Chicago Press.

Cadwallader, M. (1996). Urban geography. An analytical approach. New Jersey: Prentice Hall.

Castanho, R. A., Vulevic, A., Cabezas, J., Fernández-Pozo, L., Naranjo, J. M., y Loures, L. (2017). Accessibility and connectivity - Movement between cities, as critical factor to achieve success on cross-border cooperation projects. A European analysis. Sustainable Cities and Society, 32, 181-190. DOI: https://doi.org/10.1016/j.scs.2017.03.026

Cervero, R. (1997). Tracking accessibility. Access, 11, 27-31. Recuperado de https://escholarship.org/uc/item/8j9533k8

Cervero, R., Timothy, R., y Appleyard, B. (1997). Job accessibility as a performance indicator: an analysis of trends and their social policy implications in the San Francisco Bay Area. Working Paper 692, IURD.

Chen, S., Claramunt, C., y Ray, C. (2014). A spatio-temporal modelling approach for the study of the connectivity and accessibility of the Guangzhou metropolitan network. Journal of Transport Geography, 36, 12-23. DOI: https://doi.org/10.1016/j.jtrangeo.2014.02.006

Clark, C. (1951). Urban population densities. Journal of the Royal Statistical Society, 14, 490-496.

CODESIN; MAPASIN. (2016). Avanza. Plan de movilidad Culiacán 2045. Culiacán.

Courtat, T., Douady, S., y Gloaguen, C. (2012). Centrality maps and the analysis of city street networks. value Tools ICST, s/n. DOI: https://doi.org/10.4108/icst.valuetools.2011.245740

Crucitti, P., Latora, V., y Porta, S. (2006). Centrality measures in spatial networks. Physical Review E, 73(3), s/n. DOI: https://doi.org/10.1103/PhysRevE.73.036125

Demšar, U., Špatenková, O., y Virrantaus, K. (2008). Identifying critical locations in a spatial network with graph theory. Transactions in G/S, 12(1), 61-82. DOI: https://doi.org/10.1111/j.1467-9671.2008.01086.x

Farrington, J. (2007). The new narrative of accessibility: its potential contribution to discourses in (transport) geography. Journal of Transport Geography, 15(5), 319-330. DOI: https://doi.org/10.1016/j.jtrangeo.2006.11.007

Figueroa, O., y Rozas, P. (2005). Conectividad, ámbitos de impacto y desarrollo territorial: el caso de Chile. Santiago de Chile: CEPAL.

García-López, M.A. (2007). Estructura espacial del empleo y economías de aglomeración. El caso de la industria de la Región Metropolitana de Barcelona. ACE: Architecture, City and Environment, 2(4), 519-553. DOI: https://doi.org/10.5821/ace.v2i4.2388

Garrocho, C., y Campos, J. (2006). Un indicador de accesibilidad a unidades de servicios clave para ciudades mexicanas: fundamentos, diseño y aplicación. Economía, sociedad y territorio, 6(22), 349397. DOI: https://doi.org/10.22136/est002006262

ACE, 16 (47) CC BY-ND 3.0 ES | UPC Barcelona, España | Accesibilidad urbana y conectividad de los centros de empleo en Culiacán. DOI: http://dx.doi.org/10.5821/ace.16.47.9694 
Geurs, K. (2006). Accessibility, land use and transport. Accessibility evaluation of land use and transport developments and policy strategies. Eburon Uitgeverij BV.

Geurs, K., y van Eck, J. (2001). Accessibility measures: review and applications. Bilthoven, Utrecht: National Institute of Public Health and the Environment.

Geurs, K., y van Wee, B. (2004). Accessibility evaluation of land-use and transport strategies: review and research directions. Journal of Transport Geography, 12(2), 127-140. DOI: https://doi.org/10.1016/j.jtrangeo.2003.10.005

Giuliano, G., y Small, K. (1991). Subcenters in Los Angeles Region. Regional Science and Urban Economics, 21(2), 163-182. DOI: https://doi.org/10.1016/0166-0462(91)90032-1

González, S. (2011). División social del espacio: la ciudad y sus territorios. En La integración de la dimensión espacial en las ciencias sociales y humanidades: presentación de un proyecto interdisciplinario (p. s/n). Ciudad de México: Universidad Autónoma Metropolitana. Recuperado de https://www.academia.edu/5065282/Divisi\%C3\%B3n Social del espacio ciudad ciudad y sus territ orio

Hannemann, S., y Derudder, B. (2014). An alternative approach to the calculation and analysis of connectivity in the World City Network. Environment and Planning B: Planning and Design, 41(3), 392412. DOI: https://doi.org/10.1068\%2Fb39108

Harris, C., y Ullman, E. (1945). The nature of cities. The ANNALS of the American Academy of Political and Social Science, 242(1), 7-17.

Hillier, B., y Hanson, J. (1989). The social logic of space. Cambridge: Cambridge University Press.

Hillier, B., y Hanson, J. (1999). Space is the machine: a configurational theory of architecture. Cambridge: Cambridge University Press.

Hoyt, H. (1939). The structure and growth of residential neighborhoods in american cities. Washington, D.C.: Federal Housing Administration.

INEGI. (2010). Censo de población y vivienda 2010. Instituto Nacional de Estadística y Geografía. Recuperado de https://www.inegi.org.mx/programas/ccpv/2010/

INEGI. (2015). Encuesta Intercensal 2015. Instituto Nacional de Estadística y Geografía. Recuperado de https://www.inegi.org.mx/programas/intercensal/2015/

INEGI. (2019). Directorio Estadístico Nacional de Unidades Económicas. Instituto Nacional de Estadística, Geografía e Informática. Recuperado de https://www.inegi.org.mx/app/mapa/denue/

INEGI. (2019). Marco Geoestadístico. Instituto Nacional de Estadística, Geografía e Informática. Recuperado de https://www.inegi.org.mx/temas/mg/

Litman, T. (2020). Evaluating Accessibility for Transport Planning. Measuring People's Ability to Reach Desired Goods and Activities. Victoria Transport Policy Institute. Recuperado de http://www.vtpi.org/access.pdf

ACE, 16 (47) CC BY-ND 3.0 ES | UPC Barcelona, España | Accesibilidad urbana y conectividad de los centros de empleo en Culiacán. DOI: http://dx.doi.org/10.5821/ace.16.47.9694 
Liu, X., Dai, L., y Derudder, B. (2017). Spatial inequality in the southeast assian intercity transport network. Geographical Review, 1072), 317-335. DOI: https://doi.org/10.1111/j.1931-0846.2016.12181.x

McDonald, J. F., y McMillen, D. P. (1990). Employment subcenters and land values in a polycentric urban area: the case of Chicago. Environment and Planning A, 22, 1561-1574.

Mills, E. S. (1972). Studies in the structure of the urban economy. Baltimore: The Johns Hopkins Press.

Miralles-Guasch, C. (2002). Ciudad y transporte. El binomio imperfecto. Barcelona: Ariel.

ONU-Hábitat. (2015). Reporte nacional de movilidad urbana en México 2014-2015. México: ONUHábitat. Recuperado de https://publicacionesonuhabitat.org/onuhabitatmexico/Reporte-Nacionalde-Movilidad-Urbana-en-Mexico-2014-2015.pdf

Porta, S., Crucitti, P., y Latora, V. (2006). The network analysis of urban streets: a primal approach. Environment and Planning B: planning and design, 33(5), 705-725. DOI: https://doi.org/10.1068/b32045

Rodrigue, J., Comtois, C., y Slack, B. (2006). The geography of transport systems. Abingdon: Routledge.

Ruiz, N., Roca, J., y Moix, M. (2012). Análisis de la estructura metropolitana mediante la detección de subcentros de empleo: el caso de Bogotá. ACE: Architecture, City and Environment, 6(18), 277-304. DOI: http://doi.org/10.5821/ace.v6i18.2554

Sarlas, G., Páez, A., y Axhausen, K. (2020). Betweenness-accessibility: estimating impacts of accessibility on networks. Journal of Transport Geography, 84, s/n. DOI: https://doi.org/10.1016/j.jtrangeo.2020.102680

Sevtsuk, A., y Mekonnen, M. (2012). Urban network analysis. A new toolbox for ArcGIS. Revue internationale de géomatique, 22(2), 287-305. DOI: https://doi.org/10.3166/rig.22.287-305

Sin Tráfico. (2017, Diciembre). ¿Qué tan lejos puedes llegar en sólo 30 minutos? Recuperado de http://sintrafico.com/blog/qu\%C3\%A9-tan-lejos-puedes-llegar-en-s\%C3\%B3lo-30-minutos/

Suárez, M., y Delgado, J. (2007). Estructura y eficiencia urbanas. Accesibilidad a empleos, localización residencial e ingreso en la ZMCM 1990-2000. Economía, sociedad y territorio, V/(23), 693-724. Recuperado de https://www.redalyc.org/pdf/111/11102305.pdf

ACE, 16 (47) CC BY-ND 3.0 ES | UPC Barcelona, España | Accesibilidad urbana y conectividad de los centros de empleo en Culiacán. DOI: http://dx.doi.org/10.5821/ace.16.47.9694 